\title{
THERMALLY-DRIVEN EJECTOR FOR VACUUM FREEZING DESALINATION AT THE TRIPLE POINT
}

\author{
Jianjian Wang*, Fangyu Cao \\ Advanced Cooling Technologies, Inc., Lancaster, PA 17601, USA
}

\begin{abstract}
Recently an energy-efficient desalination process based on spray vacuum freezing of seawater at the triple point was developed. During this process, the freezing and evaporation of the water happen simultaneously at the triple point with net-zero thermal energy consumption. One of the most critical challenges in this technology is to continuously remove the vapor generated during triple-point freezing-evaporation process, since the pressure in the vacuum freezing chamber needs to be maintained at or below a level corresponding to the triple point of water. The removed vapor is transferred to a water regenerator and condensed on ice to produce liquid freshwater. The electrical energy consumption for this vapor compression and transport process can be substantial if a compressor is used. In this work, we designed and manufactured an innovative ejector system which can be driven by lowgrade waste heat, therefore significantly reduce the energy cost. Another very important feature of this ejector system is that it can create ultralow pressure at the exit of the primary nozzle. Therefore, the low-pressure vapor generated in the vacuum freezing chamber can be continuously sucked into the ejector as entrained flow, which is extremely difficult to achieve in traditional commercial ejector systems. Applications that can directly benefit from the use of this technology include seawater desalination, brackish water treatment, as well as fresh water supply for remote communities or dry regions where solar thermal energy or low-grade waste heat is abundant.
\end{abstract}

KEY WORDS: Desalination, Ejector, Vacuum Freezing, Triple Point, Low-Grade Waste Heat

\section{INTRODUCTION}

Fresh water is vital to human beings and the development of modern society. However, $97 \%$ of the earth's water is seawater which is not suitable for human consumption without treatment. [1] Thus, desalination technologies are required to convert this vast volume of seawater into a usable resource. The process of vacuum freezing desalination is based on the natural phenomenon of pure ice formation in a saline solution such as seawater. In this process, impurities tend to remain in the liquid phase, leaving a pure solid phase, i.e., ice. The heat of fusion of ice $H_{f}$ is $334 \mathrm{~kJ} / \mathrm{kg}$ at the melting point of ice, which is nearly $1 / 7$ of the heat of vaporization of water $\left(H_{\text {vap }}=2500 \mathrm{~kJ} / \mathrm{kg}\right)$ at the same temperature and pressure. When freezing occurs at the triple point of water, vapor and crystalline ice will be formed simultaneously from liquid water without heat input. The energy is balanced with the endothermic vaporization and exothermic freezing:

$$
m_{s} H_{f}=m_{v} H_{v a p}
$$

where $m_{s}$ and $m_{v}$ are the mass of solid ice and vapor generated from the liquid water, respectively. The net thermal energy consumption for the phase transition desalination processes are zero, during which about $7 / 8$ of the fresh water extracted from seawater is converted into ice and about 1/8 to vapor. The ice and vapor can then be transported to a water regeneration chamber to produce liquid fresh water by the concurrent melting and condensation process at the interface of ice and vapor. Since the amount of vapor to be transported in the 
process is only about one eighth of the total processing water, it requires much less pumping power. This low energy consumption is one of the main reasons for the continuous interest in vacuum freezing desalination technology. In addition, the low operation temperature (less than $0^{\circ} \mathrm{C}$ ) reduces the corrosion issue significantly, which allows the use of much lower cost engineering materials.

However, there has not yet been a successful commercial vacuum freezing process in desalination due to a few challenges. First, the subcooling effect in the water can significantly reduce the freezing point to a level that is much lower than the triple point temperature. There will be no ice formation in this case, even when the temperature of liquid water is dropped to far below $0^{\circ} \mathrm{C}\left(\right.$ e.g., $\left.-20^{\circ} \mathrm{C}\right)$ sometimes. Then the fresh water production rate will be dramatically reduced. To overcome this subcooling issue, we have developed a specific copper-dope $\mathrm{AgI}$ nucleating agent $\left(\mathrm{Ag}_{0.7} \mathrm{Cu}_{0.3} \mathrm{I}\right)$ recently. [2] With this innovative doped nucleating agent, the subcooling of water was suppressed to $1^{\circ} \mathrm{C}$, much lower than $4^{\circ} \mathrm{C}$ of conventional undoped AgI nucleating agent. Our model showed that the energy consumption for the vapor transport process can be reduced to only $1.4 \mathrm{kWh}$ per cubic meter fresh water due to the significant subcooling suppression, $48 \%$ lower than using conventional undoped nucleating agent and 83\% lower than that without using nucleating agent. [2-3] Second, the surface area of liquid-vapor interface involved in conventional vacuum freezing process is quite limited due to the bulk state of water, which significantly affects the heat transfer between the vapor phase and condensed phase. Additional cooling and ice handling equipment (e.g., use agitator to break bulk ice into small pieces) may be needed. To address the limited heat transfer area and ice handling issue, we have proposed to use spray freezing instead bulk freezing method to significantly increase the phase transition interface area and better control of ice form process. [3]

Another challenge in the vacuum freezing desalination process is the vapor transportation from the freezing chamber at sub-triple-point pressure to the water regenerator. It requires a certain pressure higher than the saturated vapor pressure to regenerate liquid water by condensing vapor on ice. A vapor compression process is then required to bring the low-pressure vapor from the freezing chamber to the water regenerator. The energy consumption for vapor compression is the major operation cost for vacuum freezing desalination, and the energy cost of the vacuum freezing desalination is largely determined by the pressure difference between the freezing chamber and the water regenerator. In this work, we developed an innovative ejector system, which could be driven by low-grade waste heat, to entrain the very-low-pressure vapor (at sub-triple-point pressure) from the vacuum freezing chamber and discharge it to the water regenerator at higher pressure.

\section{EXPERIMENTAL SYSTEM}

The ejector can be viewed as a fluid compression system that uses a high-pressure fluid (e.g., high-pressure steam), termed the primary flow, to entrain a secondary flow at a much lower pressure and discharges the fluid mixture at an intermediate pressure. [4] For the specific application of vapor transportation in the vacuum freezing desalination process, we used the ejector to transfer the vapor generated in the freezing chamber at sub-triple-point pressure to the water regenerator at a higher pressure.

The ejector we desired should be driven by low-grade thermal energy so that it could utilize low-grade waste heat or solar thermal energy in practice when this technology is fully developed. For demonstration purpose, we used an electrical heater that mimics the solar heating effect to heat a boiler to generate steam as the primary flow at our desired temperature and pressure. The suction port of the ejector is connected with the freezing chamber, and the discharge port of the ejector is connected to a water regenerator. In this demonstration work, we used a coil-type condenser to replace the water regenerator. The circulating refrigerant temperature is controlled to be $-10^{\circ} \mathrm{C}$ so that the vapor discharged from the ejector exit will condense immediately and form ice on the condenser coil. Schematic of our experimental setup for this demonstration work is shown in Figure 1. For practical vacuum freezing desalination plant, the ice brine slurry in the sprayed vacuum freezing chamber will be sent to a washer which separates the pure ice and concentrated brine. Then the ice will be transferred to the water regenerator, and vapor from the ejector exit will condense on the ice. Part of the fresh water produced in the water regenerator will return back to the reservoir tank of the ejector, and the rest of fresh water is collected and can be used for different purposes (e.g., irrigation, drinking, etc.). 


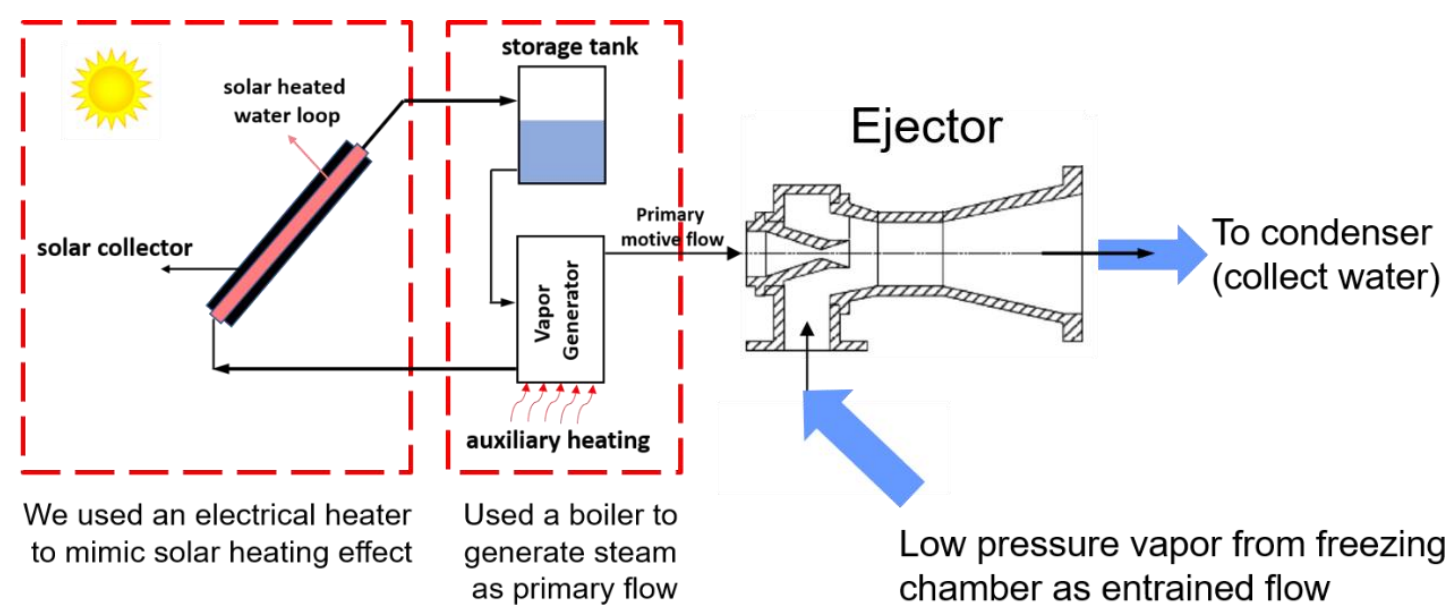

Figure 1. Schematic of the experimental setup for the ejector system that connects steam generator/boiler (provides primary flow), freezing chamber (provides suction/entrained flow) and condenser (collects water from primary and entrained flows).

The ejector is the most critical component in our vapor pumping system. It connects the vapor generator/boiler, freezing-desalination chamber and condenser (or water regenerator). Precise control on the pressures at different parts is critical for achieving desired performance. Since the pressure of entrained flow (from freezing chamber) is very low, less than $\sim 600 \mathrm{~Pa}$, the primary flow (from the boiler) must be able to create an even lower pressure at the exit of primary nozzle, otherwise the vapor generated in the freezing chamber cannot be transported to the condenser and the triple-point freezing desalination cannot be sustained. Due to the very special operation condition in our system, there is no commercially available ejector that could satisfy our requirement (i.e., very low pressure entrained flow). Based on 1-D ejector theory, [5-6]

$$
\frac{P_{p}}{P_{\text {exit }}} \approx\left(1+\frac{\gamma-1}{2} M^{2}\right)^{\frac{\gamma}{\gamma-1}}
$$

we can see that, for given pressure in the primary flow $P_{p}$, if we want to achieve very low pressure at the exit of primary nozzle $P_{\text {exit }}$, the Mach number of the flow at the primary nozzle exit $M$ needs to be large. This Mach number is mainly determined by the geometry of the primary nozzle:

$$
\left(\frac{A_{\text {exit }}}{A_{t}}\right)^{2}=\left(\frac{d_{\text {exit }}}{d_{t}}\right)^{4} \approx \frac{\left[\frac{2}{\gamma+1}\left(1+\frac{\gamma-1}{2} M^{2}\right)\right]^{\frac{\gamma+1}{\gamma-1}}}{M^{2}}
$$



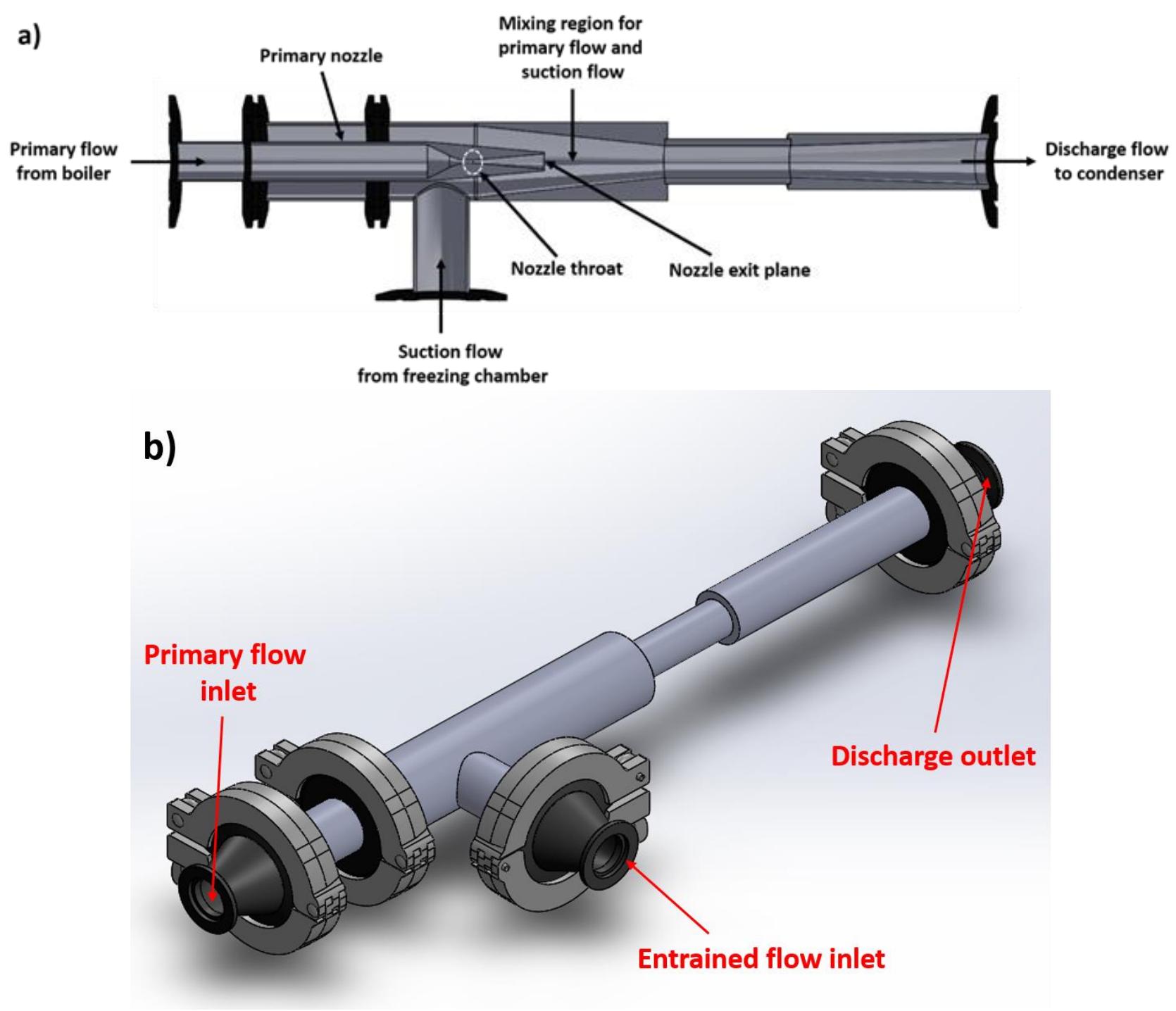

Figure 2. a) Cross-sectional view of the ejector internal structure. b) Solidworks design of the ejector.

Therefore, to achieve a supersonic flow with a large Mach number at the primary nozzle exit, the ratio of the cross-section areas at primary nozzle exit and throat also needs to be large, i.e., we need have a very narrow throat for the primary nozzle. Figure 2 shows the internal structure of our designed ejector and the appearance of the ejector. The primary nozzle throat diameter is only $1.4 \mathrm{~mm}$, and the area ratio $A_{\text {exit }} / A_{t}$ is about 39 . This ejector was then assembled with the vapor generator (boiler), freezing chamber and condenser chamber. The complete system of vacuum freezing triple-point desalination is shown in Figure 3. 


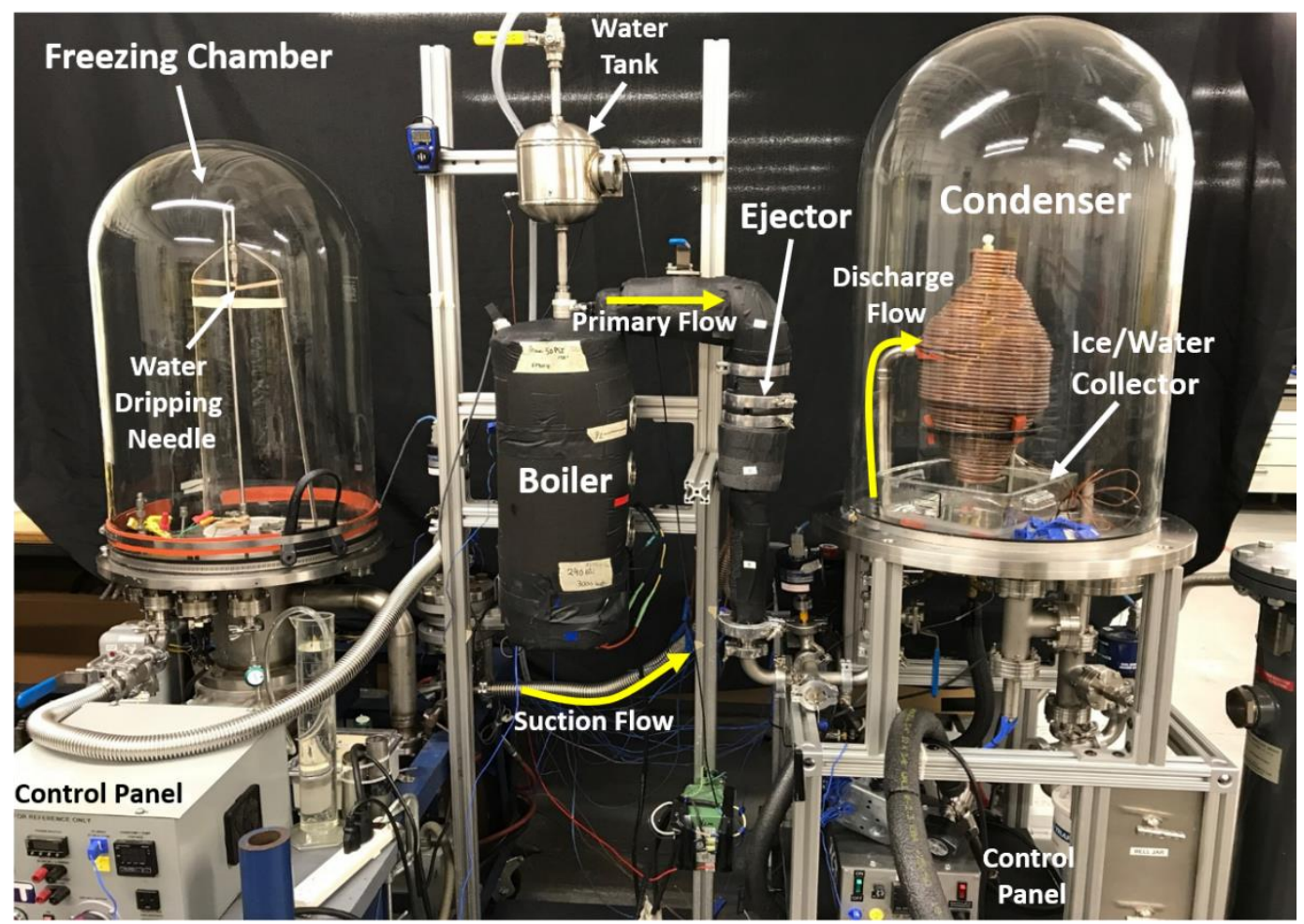

Figure 3. Experimental setup for the complete system of vacuum freezing triple-point desalination.

\section{RESULTS AND DISCUSSIONS}

Before the experimental demonstration, the valve that controls the boiler is closed, and the freezing chamber and condenser chamber are pumped down to a pressure below $100 \mathrm{~Pa}$. The water in the boiler is heated to a temperature corresponding to the typical low-grade waste heat temperature, ranging from $60-110^{\circ} \mathrm{C}$. When the boiler valve is open, the steam generated in the boiler flows through the ejector primary nozzle, reaching supersonic $(M>1)$ flow state and thus creating a low-pressure region at the nozzle exit. In the freezing chamber, the water is dripping through a needle (see Figure 3) into the chamber. During this process, part of the water droplets is evaporated into the vapor and sucked into the ejector as the entrained flow. Heat is removal from water droplets due to the evaporation and the rest part of the water droplets becomes ice. The entrained flow and the primary flow are mixed in the ejector and discharged to the condenser chamber. Ice is continuously formed on the condenser coil so that the pressure inside the condenser chamber can be maintained stable and the pressure inside the freezing chamber can be kept near the triple-point pressure.

The key for the success of the experimental demonstration is that the pressure inside the freezing chamber must be kept near or below the triple-point pressure, otherwise the vacuum freezing and evaporation process cannot be sustained. There is an optimal operation temperature or pressure (since $P_{p}=P_{\text {sat }}\left(T_{\text {sat }}\right)$ ) for the primary flow, for a given the ejector size and condenser capacity. If the temperature of primary flow is too low, the driving force for the ejector operation is also too small and the motive steam cannot be accelerated into high Mach number flow to create a low-pressure region at the primary nozzle exit. On the other hand, since the maximum mass flow rate $\dot{m}_{p}$ of primary flow is determined by:

$$
\dot{m}_{p}=\frac{P_{p} A_{t}}{\sqrt{T_{p}}} \sqrt{\frac{\gamma}{R}\left(\frac{2}{\gamma+1}\right)^{\frac{\gamma+1}{\gamma-1}}} \sqrt{\eta_{p}} \propto \frac{P_{p}}{\sqrt{T_{p}}}
$$

i.e., the primary flow rate increases rapidly with the temperature, if the temperature of the primary flow is too high, the rate of vapor flowing into the condenser chamber is also very high. The condenser must be able to condense a 
large amount of vapor into ice, otherwise the pressure $P_{b}$ in the condenser will continuously increase. Empirically, the freezing chamber pressure $P_{S}$, condenser pressure $P_{b}$ and primary flow pressure are related as $P_{S} \propto \frac{A P_{b}-P_{p}}{B}$, where $A$ and $B$ are empirical constants. As the pressure in the condenser continuously increases, the pressure in the freezing chamber will also increase and cannot be maintained near or below the triple-point pressure.
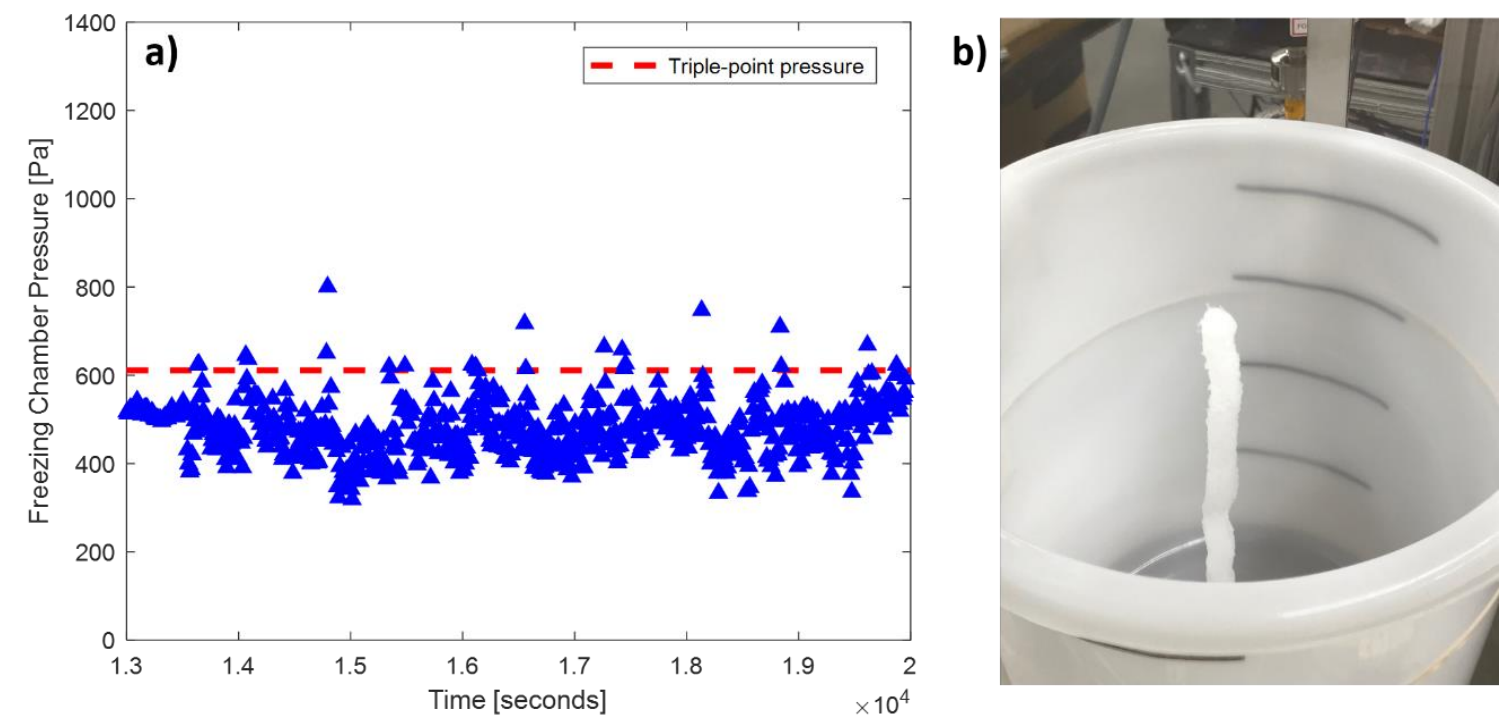

Figure 4. a) The steady state pressure in the freezing chamber when the boiler temperature is $80^{\circ} \mathrm{C}$. The pressure fluctuates around $470 \mathrm{~Pa}$, which is below the triple-point pressure of water. b) As the water drips out of the needle inside the freezing chamber, the evaporation at a pressure below the triple point results in the formation of ice inside the freezing chamber.

We tested the ejector system at different temperatures for the primary flow, ranging from $60^{\circ} \mathrm{C}$ to $110^{\circ} \mathrm{C}$. The temperature of the primary flow is directly determined by the boiler temperature. And we found that when the boiler temperature is $80^{\circ} \mathrm{C}$, the pressure in the freezing chamber reaches minimum $\sim 470 \mathrm{~Pa}$ (see Figure $4 \mathrm{a}$ ). Since this pressure is below the triple-point pressure of water, as water is dripping out of the needle in the freezing chamber (see Figure 3), the evaporation at a pressure below the triple point results in the formation of ice inside the freezing chamber (see Figure 4b). From the column shape of the ice, it can be inferred that ice is formed during water droplet falling process. As the steam generator (i.e., boiler) temperature increases or decreases, i.e., deviates from the optimal operation temperature $80^{\circ} \mathrm{C}$, the pressure in the freezing chamber will increase and may be above the triple-point pressure of water (see Figure 5, e.g., when the boiler temperature is above $90^{\circ} \mathrm{C}$ or below $65^{\circ} \mathrm{C}$ ). For our system (given the ejector geometry and condenser size), the operational temperature range for the ejector is around $65-90^{\circ} \mathrm{C}$, which is in the low-grade waste heat temperature range. This operational temperature range can be tuned by the condenser size (i.e., condensation capacity) and ejector size. 


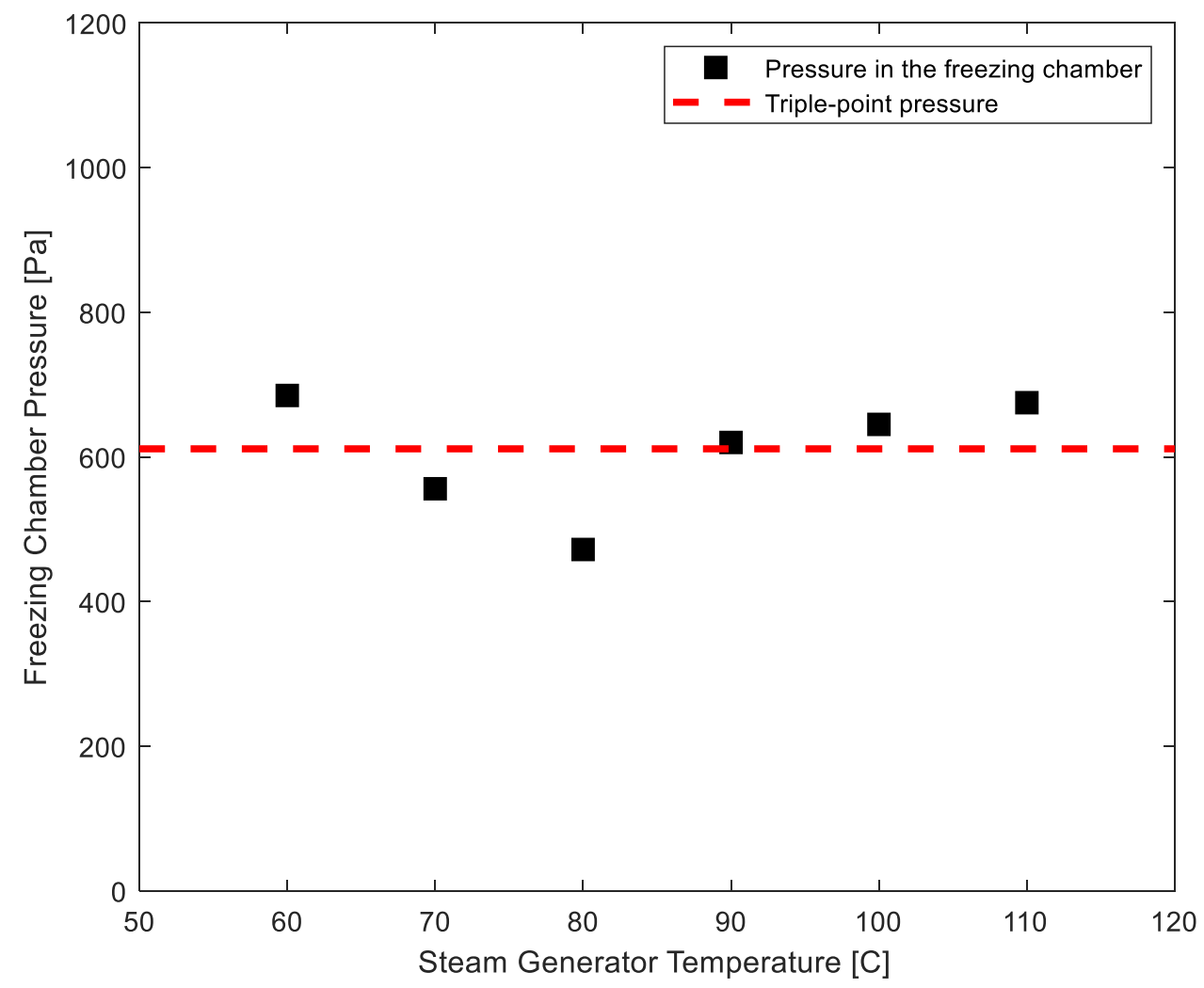

Figure 5. The steady state pressure in the freezing chamber as a function steam generator temperature (i.e., ejector primary flow temperature). For boiler temperatures at $70^{\circ} \mathrm{C}, 80^{\circ} \mathrm{C}$ and $90^{\circ} \mathrm{C}$, we observed ice formation inside the freezing chamber during the water dripping process since the pressure in the freezing chamber can be maintained near or below the triple point pressure.

\section{CONCLUSIONS}

Advanced Cooling Technologies, Inc. developed an innovative ejector system that can be used as a vapor pumping system for vacuum freezing desalination system. It can be driven by low temperature heat and thus could utilize various low-grade waste heat sources and solar thermal energy. We conducted proof-of-concept demonstration for the vacuum freezing process using our specially designed ejector system. The operational temperature range of ejector system can be tuned by the ejector geometry and condensing system capacity. The goal of this study is to demonstrate the feasibility of using thermally-driven ejector to pump vapor from the very-low-pressure freezing chamber without using an electrically-powered compressor. Further optimization of the performance needs more detailed investigations about the energy characteristics of the ejector, such as entrainment ration as a function of steam pressure and condensation pressure, the position of primary nozzle exit in the ejector, the mixing region length in the ejector, etc. Applications that can directly benefit from the use of this technology include seawater desalination, brackish water treatment, as well as fresh water supply for remote communities or dry regions where solar thermal energy or low-grade waste heat is abundant.

\section{ACKNOWLEDGMENT}

Advanced Cooling Technologies, Inc. gratefully acknowledges the support by Office of Science in U.S. Department of Energy (award \# DE-SC0015824) for the present work. The authors would like to thank Dennis Winters, Philip Texter, Max Demydovych, Dr. Chien-Hua Chen and Sean Hoenig for the support during experiments and helpful discussions. 


\section{NOMENCLATURE}

$\begin{array}{llll}H_{f} & \text { heat of fusion of ice } & (\mathrm{kJ} / \mathrm{kg}) & \\ H_{\text {vap }} & \text { heat of vaporization of water } & (\mathrm{kJ} / \mathrm{kg}) & \\ m_{v} & \text { mass of vapor } & (\mathrm{kg}) & \\ m_{s} & \text { mass of ice } & (\mathrm{kg}) & \\ P_{p} & \text { pressure of primary flow } & (\mathrm{Pa}) & \\ P_{\text {exit }} & \text { pressure at primary nozzle exit } & (\mathrm{Pa}) & \\ M & \quad \text { Mach number } & \\ \gamma & \quad \text { heat capacity ratio } & (-) \\ A_{\text {exit }} d_{\text {exit }} \quad \text { cross-section area (or diameter) at nozzle exit } & (-) & \left(\mathrm{m}^{2} \mathrm{~m}\right) \\ A_{t} d_{t} & \text { cross-section area (or diameter) at nozzle throat } & \left(\mathrm{m}^{2} \mathrm{~m}\right) \\ \dot{m}_{p} & \text { mass flow rate of primary flow } & (\mathrm{kg} / \mathrm{s}) \\ T_{p} & \text { temperature of primary flow } & (\mathrm{K}) \\ \eta_{p} & \text { isentropic coefficient of primary nozzle } & (-) \\ R & \text { gas constant } & (\mathrm{J} / \mathrm{kg}-\mathrm{K})\end{array}$

\section{REFERENCES}

[1] Ghalavand, Y., Hatamipour, M.S., Rahimi, A., “A review on energy consumption of desalination processes”, Desalin. Water Treat., 54:6, pp. 1526-1541, (2015).

[2] Cao, F.Y., Wang, J.J., "Enhanced vacuum freezing for thermal desalination at the triple point", $4^{\text {th }}$ Thermal and Fluids Engineering Conference (TFEC), April 14-17, 2019, Las Vegas, NV, USA

[3] Cao, F.Y., Zelinsky, R., Wang, J.J., "Nucleating agent enhanced thermal desalination at the triple point", $3^{\text {rd }}$ Thermal and Fluids Engineering Conference (TFEC), March 4-7, 2018, Fort Lauderdale, FL, USA

[4] Chen, J.Y., Havtun, H., Palm, B., Chen, Y., “An experimental study of vapor ejectors working with R245FA", $2^{\text {nd }}$ Thermal and Fluids Engineering Conference (TFEC), April 2-5, 2017, Las Vegas, NV, USA

[5] Huang, B.J., Chang, J.M., Wang, C.P., Petrenko, V.A., “A 1-D analysis of ejector performance”, International Journal of Refrigeration 22 (1999) 354-364

[6] El-Dessouky, H., Ettouney, H., Alatiqi, I., Al-Nuwaibit, G., "Evaluation of steam jet ejectors", Chemical Engineering and Processing 41 (2002) 551-561 